\title{
Anion-Derived Solid-Electrolyte Interphase Enables Long Life Na- Ion Batteries Using Superconcentrated Ionic Liquid Electrolytes
}

\author{
Ju Sun, ${ }^{\dagger}$ Luke A. O’Dell, ${ }^{\dagger}$ Michel Armand, ${ }^{\ddagger}$ Patrick C. Howlett, ${ }^{\dagger}$ Maria Forsyth ${ }^{\dagger *}$ \\ †Institute for Frontier Materials, Deakin University, Geelong, Victoria 3217, Australia \\ \#Basque Research and Technology Alliance (BRTA), Àlava Technology Park, Albert Einstein \\ 48, 01510, Vitoria-Gasteiz, Spain
}

\section{Experimental section}

Materials. $\mathrm{Na}$ metal was purchased from Sigma-Aldrich. Battery-grade Sodium bis(fluorosulfonyl)imide (NaFSI, 99.7\%) and N-Propyl-N-methylpyrrolidinium bis(fluorosulfonyl)imide $\left(\mathrm{C}_{3}\right.$ mpyrFSI, 99.9\%) were obtained from Solvionic Corporation. They were dried under vacuum by Schlenk line at $50{ }^{\circ} \mathrm{C}$ before use. Sodium hexafluorophosphate $\left(\mathrm{NaPF}_{6}, 98 \%\right)$, ethylene carbonate (EC, 99\%), and dimethyl carbonate (DMC, 99\%), diethyl carbonate (DEC, 99\%) were purchased from Sigma-Aldrich. EC, DMC and DEC were dried with $4 \AA$ molecular sieves (Aldrich-Aldrich) prior to use. Electrolytes were prepared by adding NaFSI into $\mathrm{C}_{3}$ mpyrFSI and EC/DMC $(1: 1$ vol\%) with the concentration of salts $3.8 \mathrm{M}$ and $1 \mathrm{M}$. The electrolyte preparation was conducted in argon-filled glovebox with $\mathrm{H}_{2} \mathrm{O}$ and $\mathrm{O}_{2}$ levels less than $0.1 \mathrm{ppm}$. The CMK (mesoporous carbon) was bought from Guangdong Canrd New Energy Technology Corporation for electrode preparation. The CMK anode was prepared by mixing CMK, carbon additives (Sigma Aldrich), carboxymethyl cellulose (CMC, Sigma-Aldrich) at a ratio of 70:15:15 and the slurry was coated on the aluminium foil. The mass loading of CMK electrode is $1 \mathrm{mg} / \mathrm{cm}^{2}$ and $2 \mathrm{mg} / \mathrm{cm}^{2}$. Kuranode hard carbon (HC) was bought from Kuraray Company. The electrode preparation is same as CMK, and the mass loading is $1 \mathrm{mg} / \mathrm{cm}^{2}$.

Electrochemistry. The R2032 half-cell was assembled by putting CMK or HC electrode (8 $\mathrm{mm}$ in diameter) as working electrode, and $\mathrm{Na}$ metal $\left(10 \mathrm{~mm}\right.$ in diameter). The Solupor ${ }^{\circledR}$ polyethylene $(19 \mathrm{~mm}$ in diameter) was used as separator between the electrodes with $50 \mu \mathrm{L}$ electrolyte in the coin cell. The half-cell was rested for $12 \mathrm{~h}$ under $50{ }^{\circ} \mathrm{C}$ oven prior to the electrochemical test. The $\mathrm{Na} / \mathrm{CMK}$ cell was cycled within the voltage range from $0.01 \mathrm{~V}$ to 3 $\mathrm{V}$. The $\mathrm{Na} / \mathrm{HC}$ cell was cycled within the voltage range from $0.01 \mathrm{~V}$ to $2 \mathrm{~V}$. Long-term cycling 
was conducted at $500 \mathrm{~mA} / \mathrm{g}$, after 5 cycles formation process at $100 \mathrm{~mA} / \mathrm{g}$. Rate capability was carried out at 100,200,500, $1000 \mathrm{~mA} / \mathrm{g}$ current density for 5 cycles individually. The cycling test was performed on Neware battery testing system. Cyclic voltammetry (CV) test was carried out at a scan rate of $0.1 \mathrm{mV} / \mathrm{s}$ and $0.1,0.2,0.5,1$ and $2 \mathrm{mV} / \mathrm{s}$ respectively for different purposes. Electrochemical Impedance Spectroscopy (EIS) was collected in a frequency range from $10^{5} \mathrm{HZ}$ to $10^{-1} \mathrm{HZ}$ with $10 \mathrm{mV}$ potential perturbation by Biologic VSP potentiostat.

Characterization. The morphology of CMK electrodes of different states (pristine, sodiated, and de-sodiated) was examined by JEOL JSM-IT300-LV scanning electron microscope at a accelerating voltage of $5 \mathrm{kV}$ and $30 \mathrm{pA}$ current. X-ray photoelectron spectroscopy (XPS) was performed on a Thermo Scientific Nexsa spectrometer equipped with a hemispherical analyzer. The incident radiation was monochromatic Al Ka X-rays $(1486.6 \mathrm{eV})$ at $72 \mathrm{~W}(6 \mathrm{~mA}$ and 12 $\mathrm{kV}, 400 \times 800 \mu \mathrm{m} 2$ spot). Survey (wide) and high-resolution (narrow) scans were recorded at analyzer pass energies of 150 and $50 \mathrm{eV}$, respectively. Survey scans were performed with a step size of $1.0 \mathrm{eV}$ and a dwell time of $10 \mathrm{~ms}$. High-resolution scans were obtained with a step size of $0.1 \mathrm{eV}$ and dwell time of $50 \mathrm{~ms}$. The base pressure in the analysis chamber was less than $5.0 \times 10-9$ mbar. A low-energy dual-beam (ion and electron) flood gun was used to compensate for surface charging. All data were processed using Casa XPS and the energy calibration was referenced to the low binding energy component of the $\mathrm{C} 1$ s peak at $284.8 \mathrm{eV}$.

Solid-state NMR experiments were collected on a $500 \mathrm{MHz}(11.7 \mathrm{~T})$ Bruker Avance III widebore spectrometer. The materials were scratched from the cycled cathodes under different sodiation states (pristine, 1.5, 0.72, 0.01, 2.2, 3), and rinsed thoroughly by dimethyl carbonate (DMC, $\geq 99 \%$; Sigma-Aldrich). They were then heated under vacuum overnight to remove the residual solvent. For the NMR analysis the resulting dry powders were mixed with boron nitride powder by shaking and packed into $2.5 \mathrm{~mm}$ zirconia MAS NMR rotors inside an argon glovebox. They were then transported directly into the MAS NMR probe and spun at $20 \mathrm{kHz}$ using dried air. $23 \mathrm{Na}$ spectra were acquired using a single-pulse experiment and a recycle delay of $0.5 \mathrm{~s}$ with 1000 scans acquired. 19F spectra were acquired using a Hahn echo pulse sequence with a $50 \mu$ s echo delay, a 1 s recycle delay and 1000 scans acquired. Both nuclei were referenced using solid $\mathrm{NaF}(\delta=7.4 \mathrm{ppm}$ for $23 \mathrm{Na}$ and $-224.2 \mathrm{ppm}$ for $19 \mathrm{~F})$. 
(a)

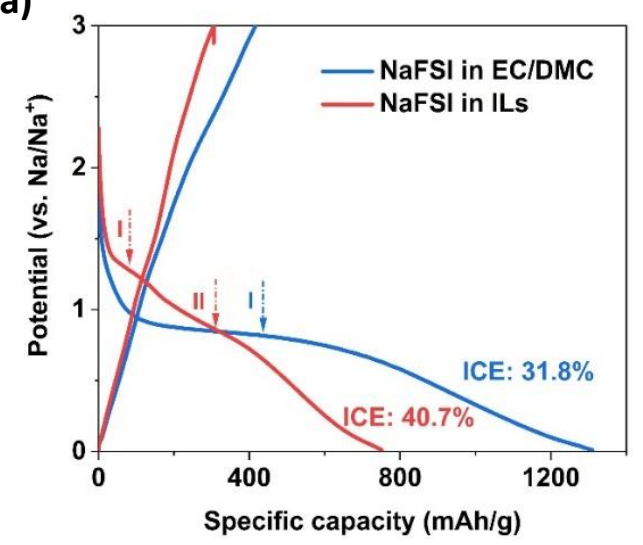

(b)

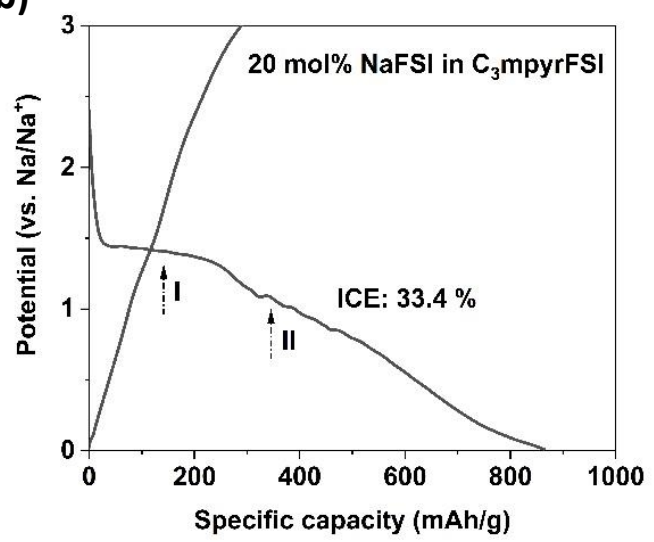

Figure S1. Galvanostatic charge/discharge curve of $\mathrm{Na} / \mathrm{CMK}$ cell at the initial cycle in (a) $1 \mathrm{M}$ NaFSI in EC/DMC and 3.9 M NaFSI in ILs electrolytes; and (b) 1.6 M NaFSI in ILs electrolyte

(a)

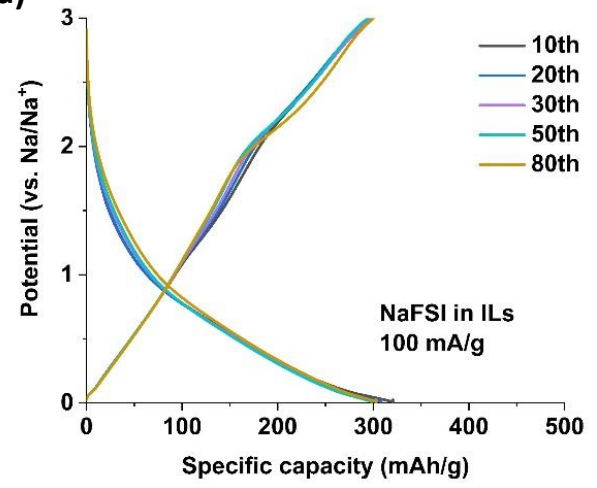

(b)

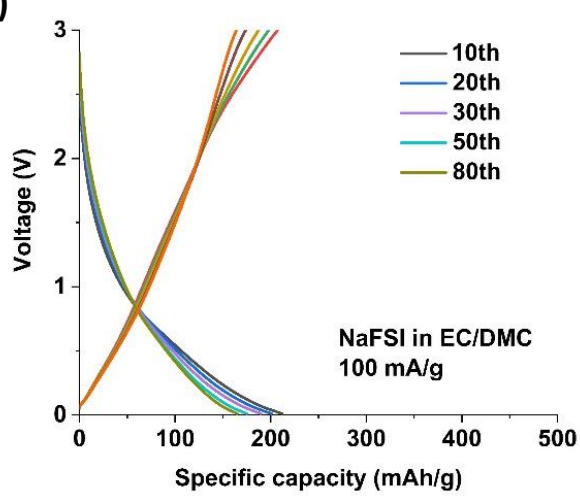

Figure S2. Galvanostatic charge/discharge curve of $\mathrm{Na} / \mathrm{CMK}$ cell at $10^{\text {th }}, \mathbf{2 0}^{\text {th }}, \mathbf{3 0}^{\text {th }}, \mathbf{5 0}^{\text {th }}$, and $80^{\text {th }}$ cycle at a current density of $100 \mathrm{~mA} / \mathrm{g}$ in (a) ILs and (b) EC/DMC electrolytes

(a)

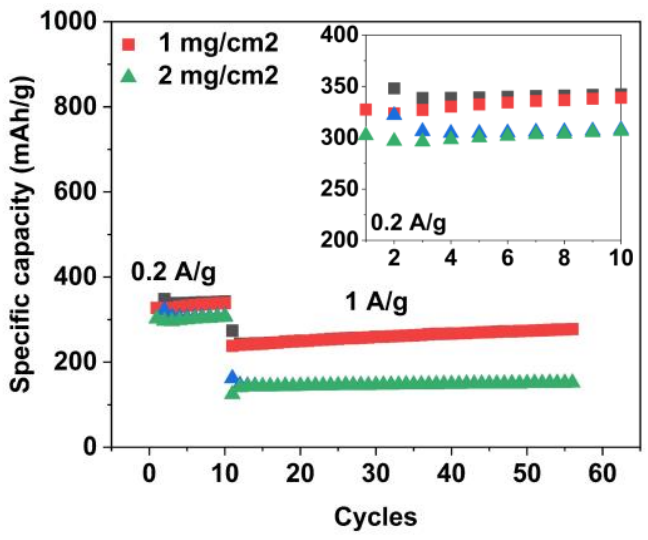

(b)

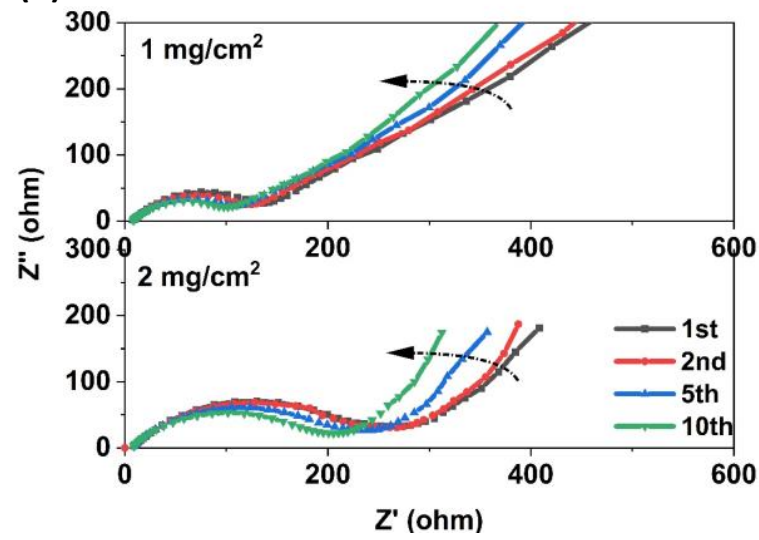


Figure S3. Cycling performance of $\mathrm{Na} / \mathrm{CMK}$ cell with CMK mass loading $1 \mathrm{mg} / \mathrm{cm}^{2}$ and $2 \mathrm{mg} / \mathrm{cm}^{2}$ in $50 \mathrm{~mol} \% \mathrm{NaFSI} / \mathrm{ILs}$, at the current density of $0.2 \mathrm{~A} / \mathrm{g}$ for the initial 10 cycles, followed by $1 \mathrm{~A} / \mathrm{g}$ for the remaining cycling (a); EIS spectra of the two CMK electrodes after $1^{\text {st }}, 2^{\text {nd }}, 5^{\text {th }}$ and $10^{\text {th }}$ cycle (b). There is little difference between the two cells when it comes to $0.2 \mathrm{~A} / \mathrm{g}$ current density, with $338 \mathrm{mAh} / \mathrm{g}$ specific capacity for $1 \mathrm{mg} / \mathrm{cm}^{2}$ and $305 \mathrm{mAh} / \mathrm{g}$ for $2 \mathrm{mg} / \mathrm{cm}^{2}$, respectively (Figure. S3a). The smaller semicircle of $1 \mathrm{mg} / \mathrm{cm}^{2}$ cell in EIS spectra, as compared with that of $2 \mathrm{mg} / \mathrm{cm}^{2}$, implies a faster reaction rate and facilitated $\mathrm{Na}$ ion diffusion kinetics throughout the $1 \mathrm{mg} / \mathrm{cm}^{2}$ mesopores (Figure. S3b). This is attributed to the fact that the high mass loading CMK electrode consumes lots of electrolyte to form thick SEI layer, and the longer permittivity time would slower the diffusion rate of $\mathrm{Na}^{+}$ion. Note that the $\mathrm{Na}^{+}$diffusion coefficient observed from the slope of the Warburg resistance in both systems keeps increasing, indicating enhanced $\mathrm{Na}^{+}$diffusion kinetics with fast $\mathrm{Na}^{+}$insertion into the CMK cathode.

(a)

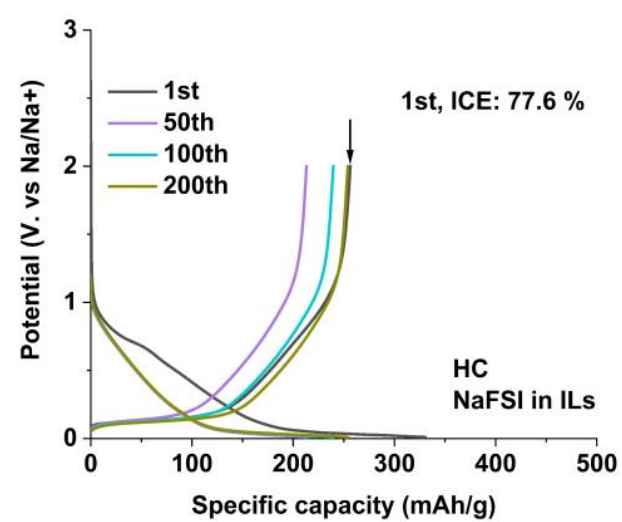

(b)

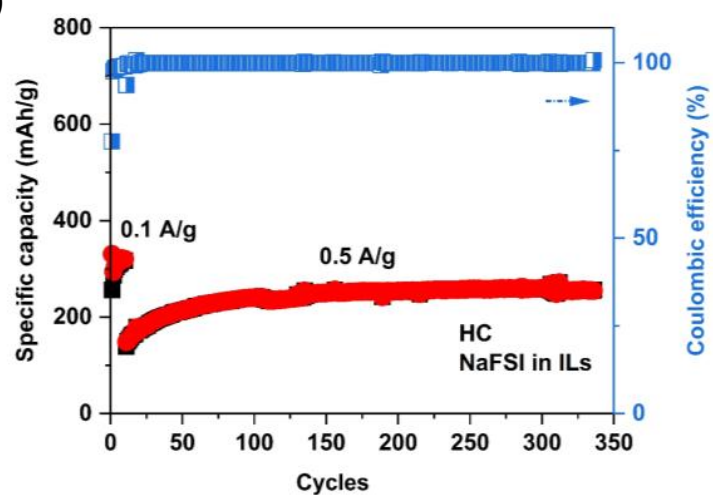

Figure S4. Galvanostatic charge/discharge curve of $\mathrm{Na} / \mathrm{HC}$ cell at $1^{\text {st }}, \mathbf{5 0}^{\text {th }}, \mathbf{1 0 0}^{\text {th }}$ and $200^{\text {th }}$ cycle in 3.8 M NaFSI in ILs electrolytes at a current density of $0.1 \mathrm{C} \mathrm{(a)}$; cycling stability tests of $\mathrm{Na} / \mathrm{HC}$ cells at the current density of $0.1 \mathrm{~A} / \mathrm{g}$ for the initial 10 cycles, followed by $0.5 \mathrm{~A} / \mathrm{g}$ for the remaining cycling (b).

The HC anode tested in ionic liquid electrolytes shows a high ICE of $77.6 \%$ (Figure. S4a) at the current density of $0.1 \mathrm{C}$, and maintains stable capacity of $240 \mathrm{mAh} / \mathrm{g}$ for over 300 cycles at $0.2 \mathrm{C}$ (Figure. S4b). This result shows the superior performance of the ILs electrolyte with carbon materials and indicates the feasibility of ILs in NIBs. 


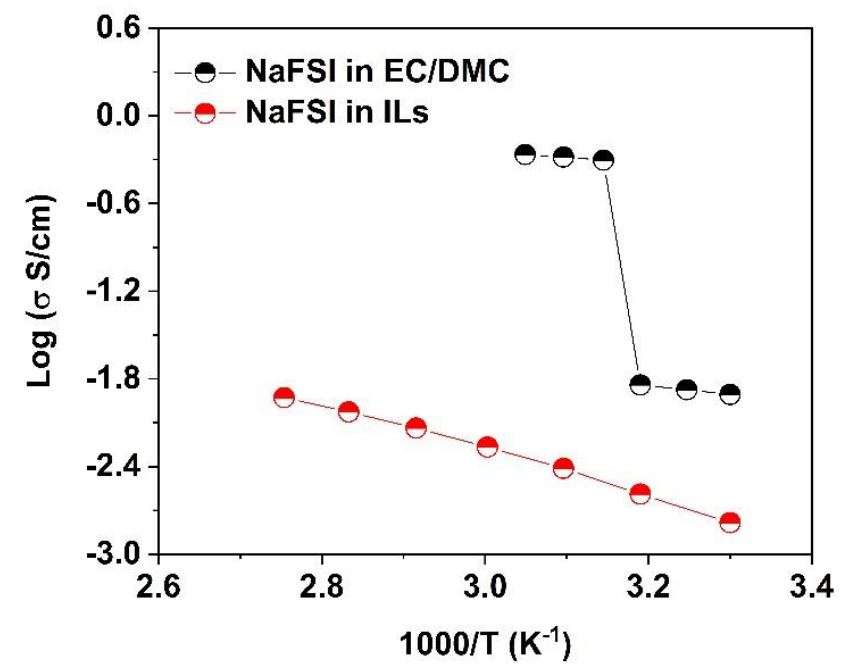

Figure S5. Ionic conductivity curves of NaFSI in EC/DMC and NaFSI in ILs

(a)

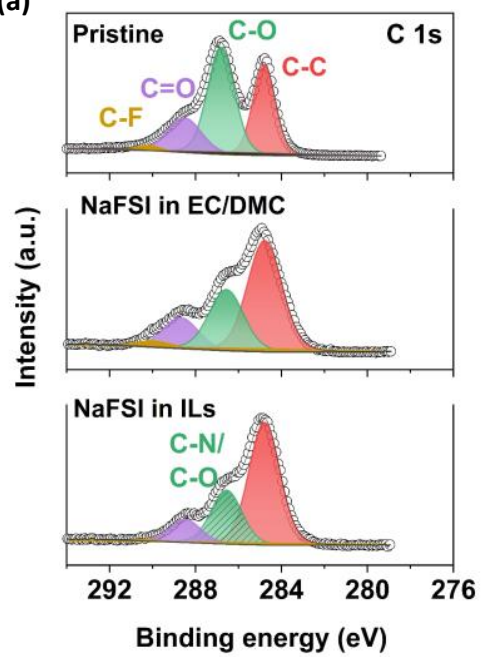

(b)
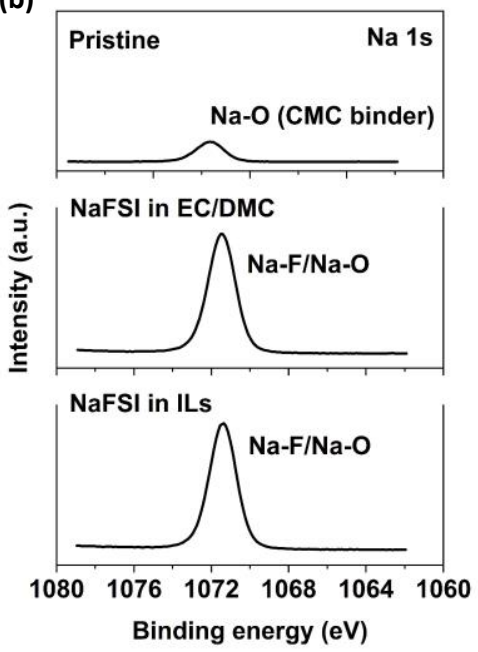

(c)
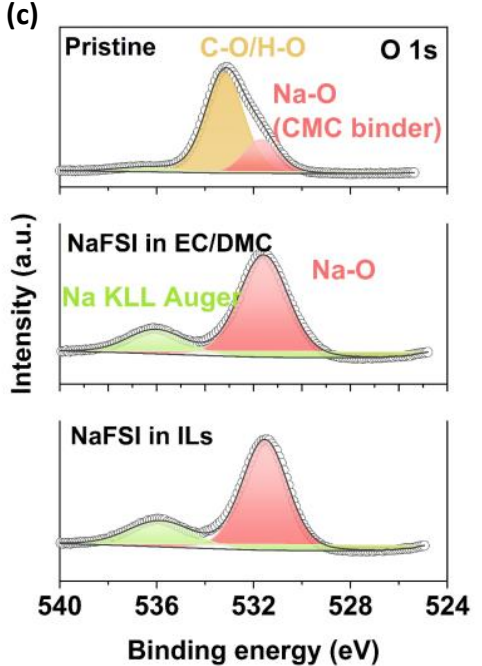

Figure S6. XPS spectra of cycled CMK electrode in the pristine electrode, carbonate electrolyte and ionic liquid electrolyte. (a-c) $\mathrm{C} 1 \mathrm{~s}, \mathrm{Na} 1 \mathrm{~s}$ and $\mathrm{O} 1 \mathrm{~s}$. 


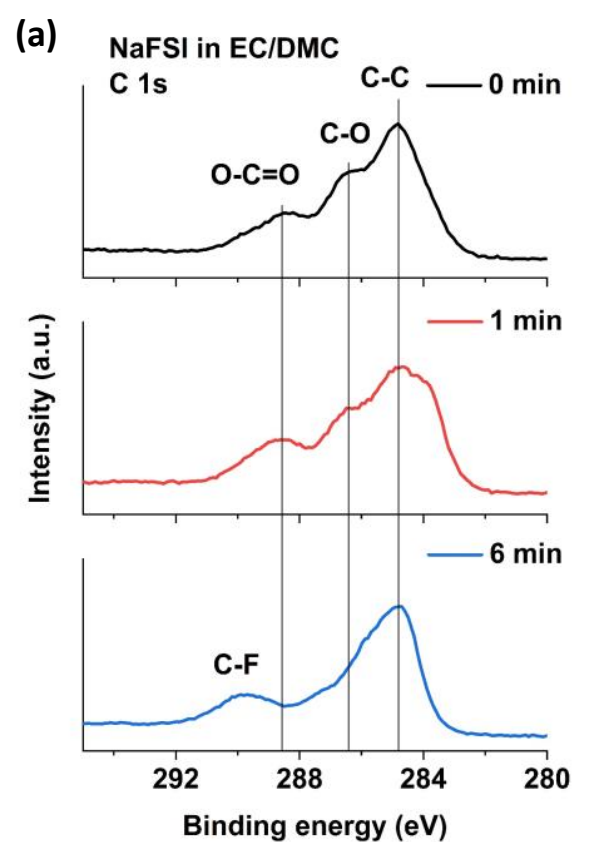

(c)

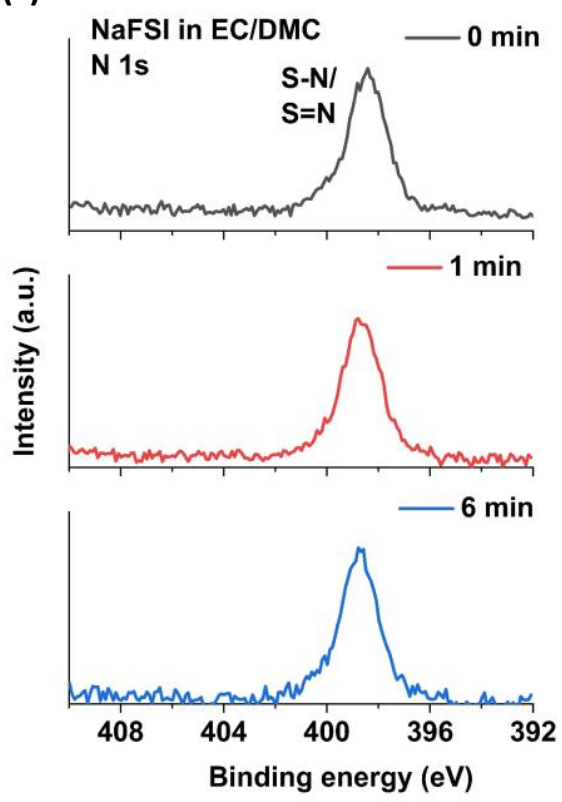

(b) NaFSI in ECDMC

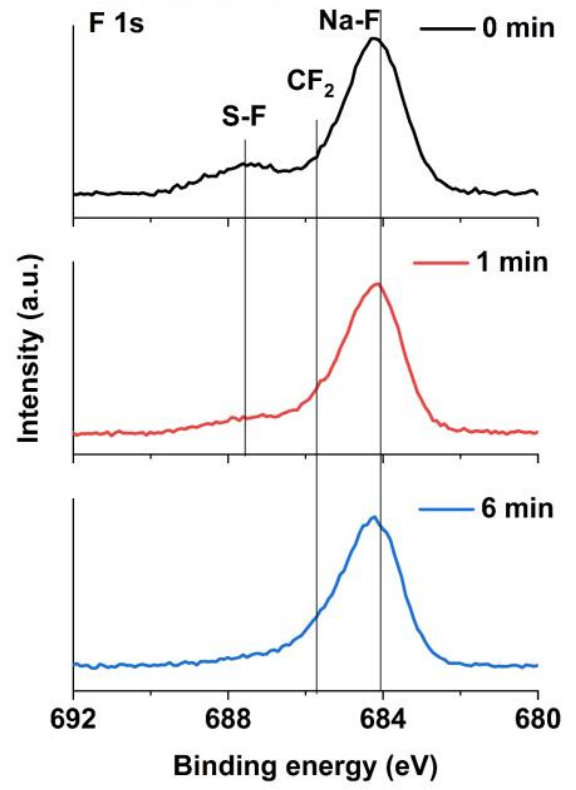

(d)

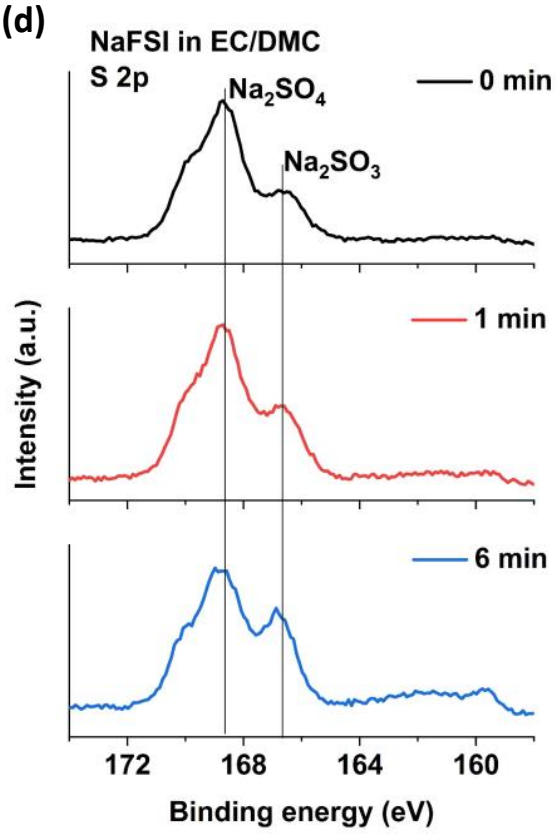

Figure S7. Etching depth profile of (a) C 1s, (b) F 1s, (c) N 1s and (d) S 2p in EC/DMC 
(a)

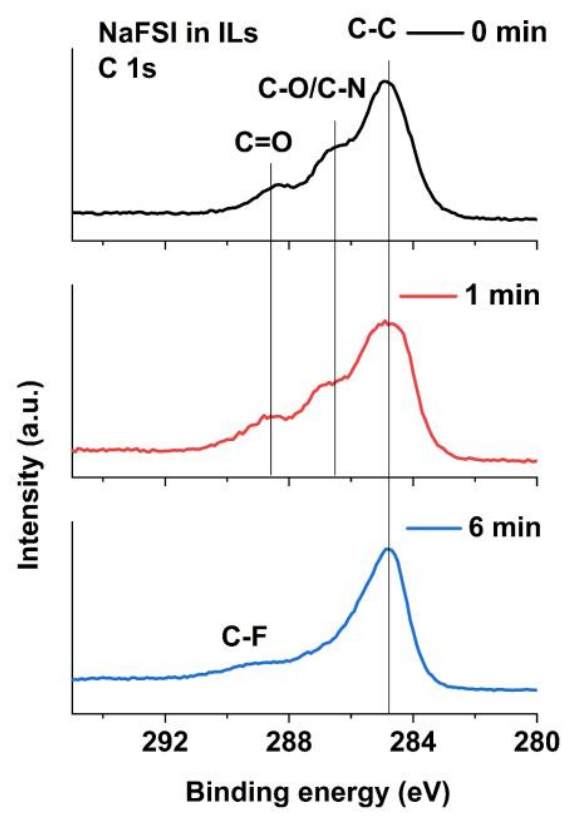

(c)

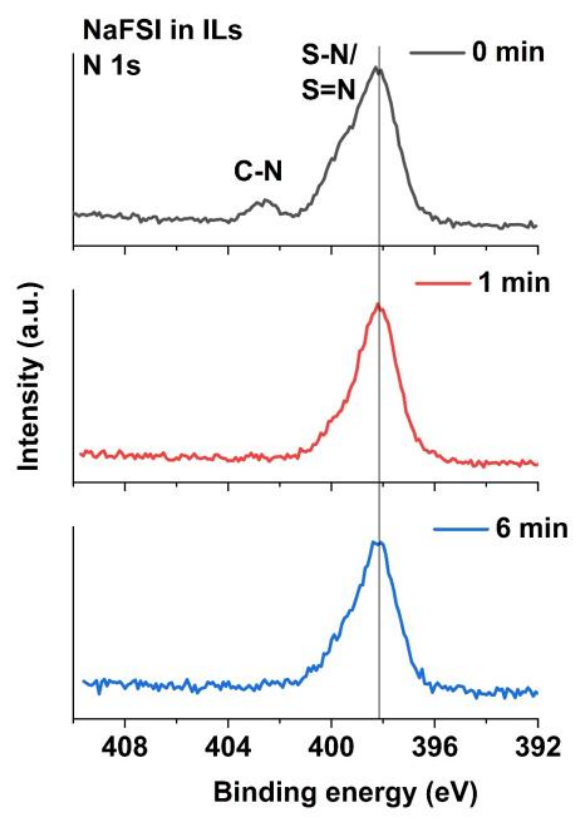

(b)

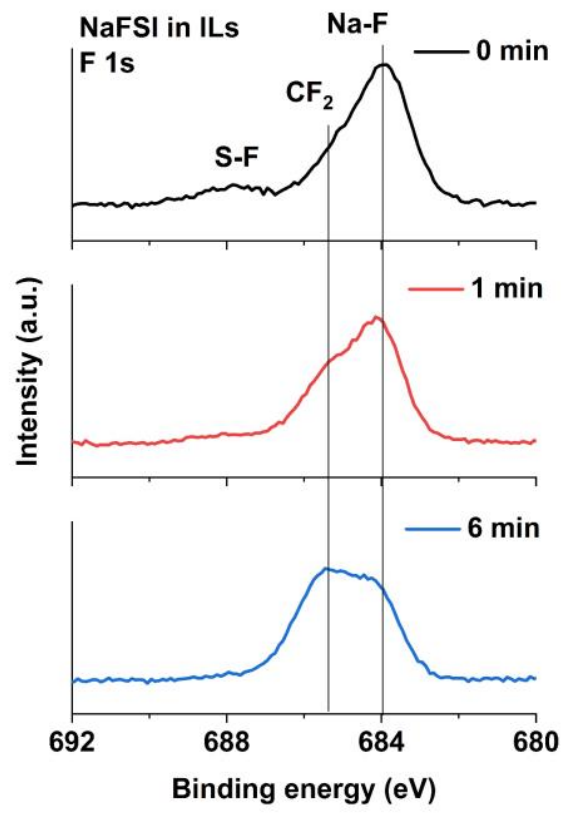

(d)

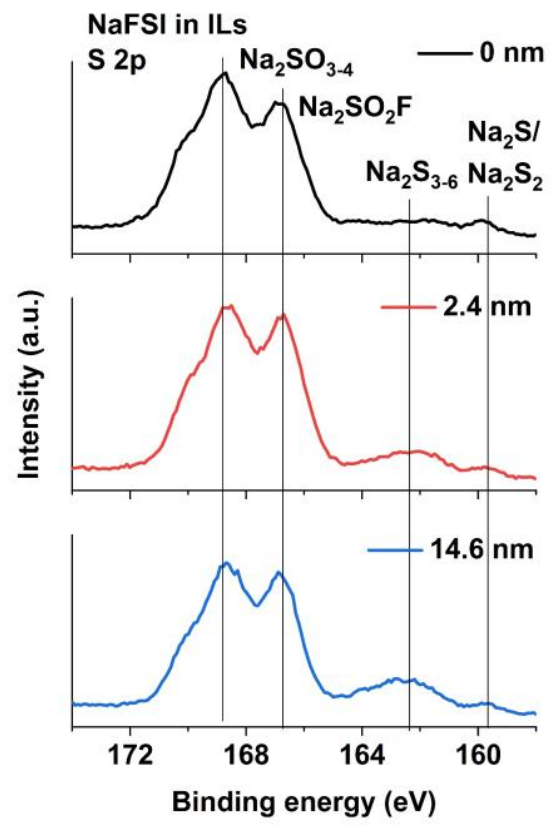

Figure S8. Etching depth profile of (a) C 1s, (b) F 1s, (c) N 1s and (d) S 2p in ILs 
(a)

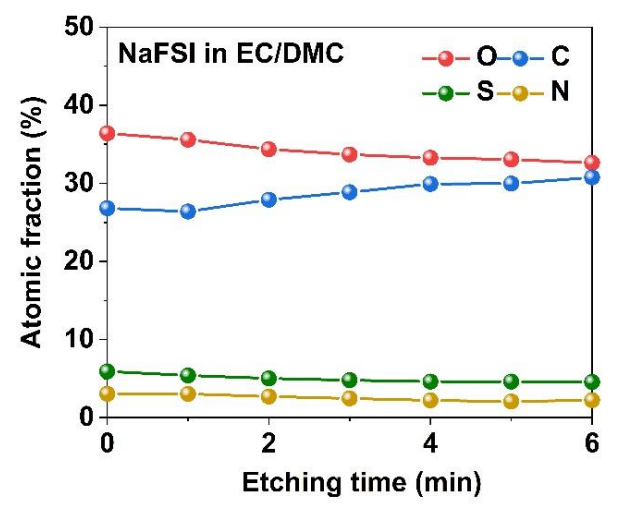

(b)

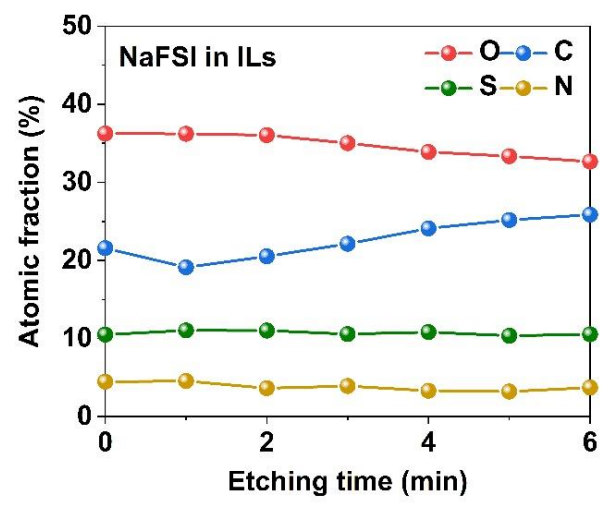

Figure S9. XPS elemental depth profile for NaFSI in EC/DMC and NaFSI in ILs.

(a)

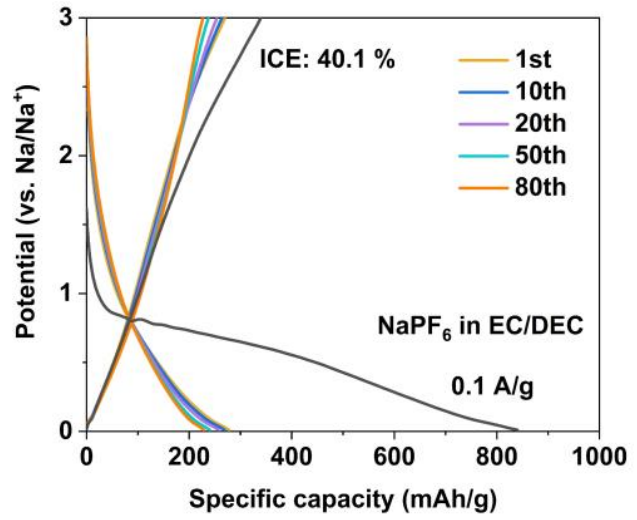

(b)

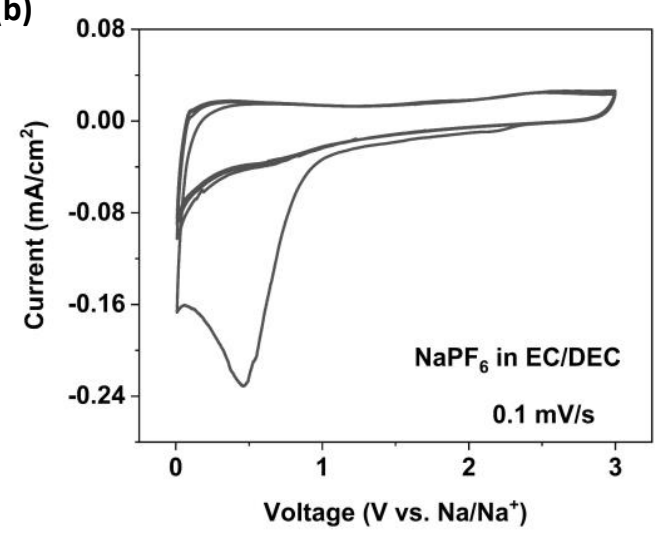

(c)

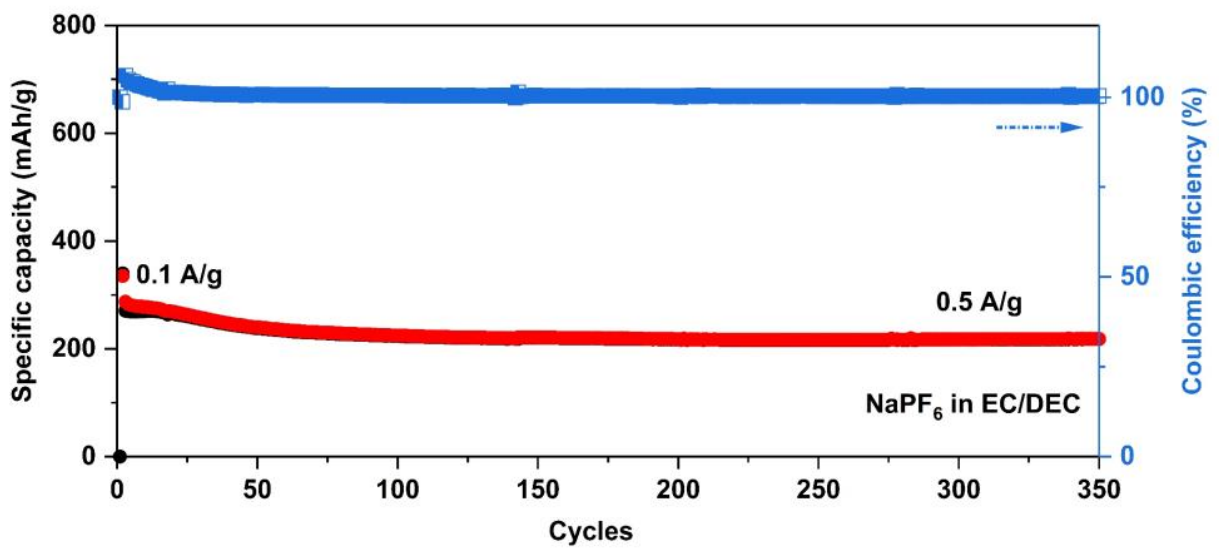

Figure S10. Galvanostatic charge/discharge curve of $\mathrm{Na} / \mathrm{CMK}$ cell in carbonate electrolytes $(1 \mathrm{M}$ $\mathrm{NaPF}_{6}$ in $\mathrm{EC} / \mathrm{DEC}$ ) at $50{ }^{\circ} \mathrm{C}$ at $0.1 \mathrm{~A} / \mathrm{g} \mathrm{(a);} \mathrm{CV}$ curve of the $\mathrm{Na} / \mathrm{CMK}$ cell at $0.1 \mathrm{mV} / \mathrm{s}$ (b); cycling stability tests of $\mathrm{Na} / \mathrm{CMK}$ cells in carbonate electrolytes ( $1 \mathrm{M} \mathrm{NaPF}_{6}$ in EC/DEC) at current density of $0.1 \mathrm{~A} / \mathrm{g}$ for the initial 10 cycles, followed by $0.5 \mathrm{~A} / \mathrm{g}$ for the remaining cycling.

The $\mathrm{Na} / \mathrm{CMK}$ cell in $\mathrm{NaPF}_{6}$ in $\mathrm{EC} / \mathrm{DEC}$ system exhibits an initial specific capacity of 840 $\mathrm{mAh} / \mathrm{g}$ with ICE of $40.1 \%$ in Figure. S10a. It shows a similar reduction peak at $0.5 \mathrm{~V}$ to NaFSI 
in EC/DMC, ascribing to the reduction of $\mathrm{NaPF}_{6}$ and organic solvents (Figure. S10b). The less electrolyte decomposition in $\mathrm{NaPF}_{6}$ in EC/DEC than that in NaFSI in EC/DMC can be explained by the strong P-F $\left(\mathrm{PF}_{6}\right)$ bond stability than S-F (FSI), undergoing less electrochemical cleavage at a relatively low potential. ${ }^{1}$ However, the reduction of organic solvents together with $\mathrm{NaPF}_{6}$ form an inorganic-organic SEI layer, leading to sluggish $\mathrm{Na}^{+}$ diffusion and low specific capacity of $219 \mathrm{mAh} / \mathrm{g}$ in Figure. S10c.
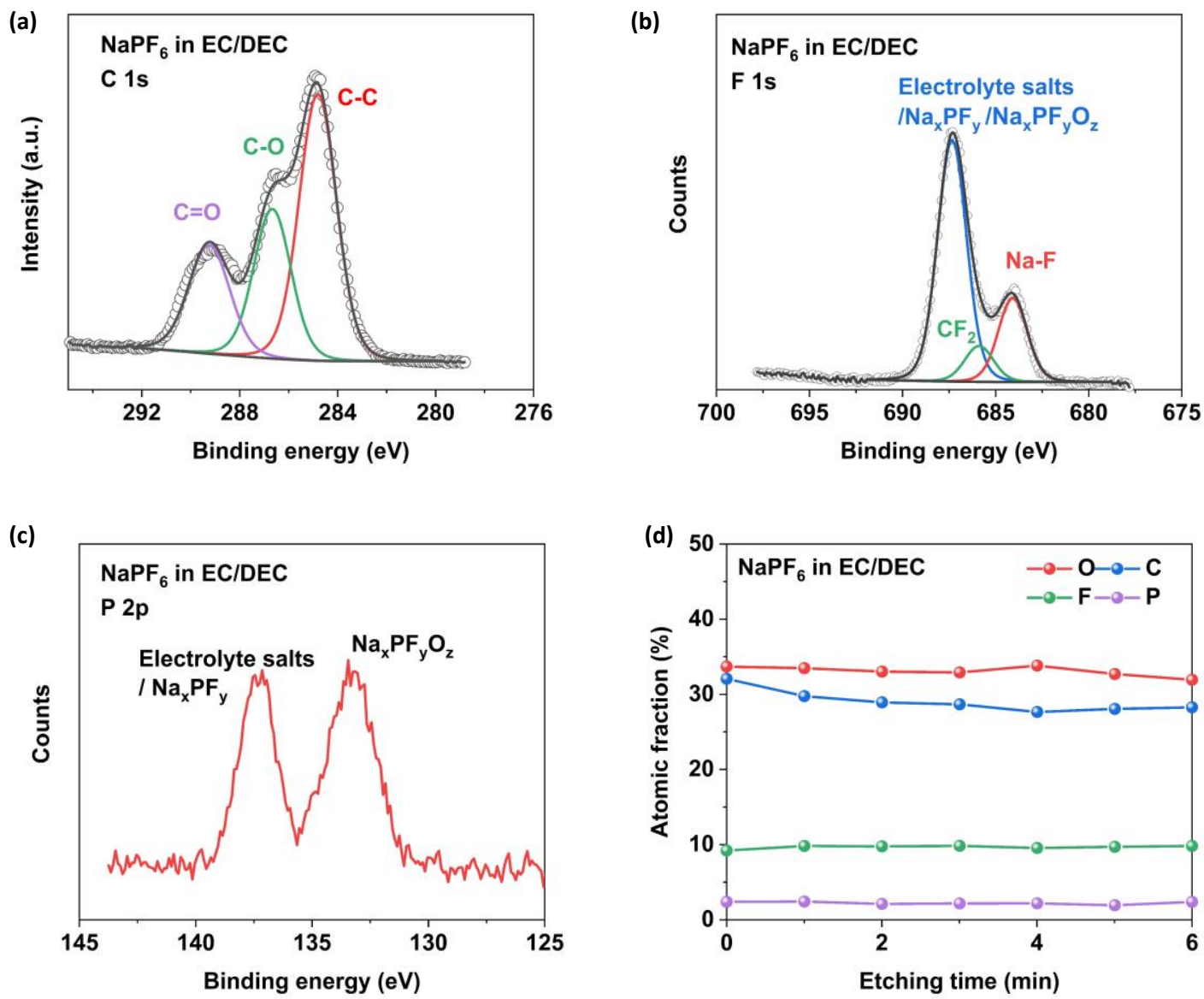

Figure S11. XPS spectra of cycled CMK electrodes ( 5 cycles, $0.01-3 \mathrm{~V}, 0.1 \mathrm{~A} / \mathrm{g}$ ) in $\mathrm{NaPF}_{6}$ in EC/DEC, C 1s (a); P 2p (b); F 1s (c) and XPS elemental depth profile (d). 
(a)

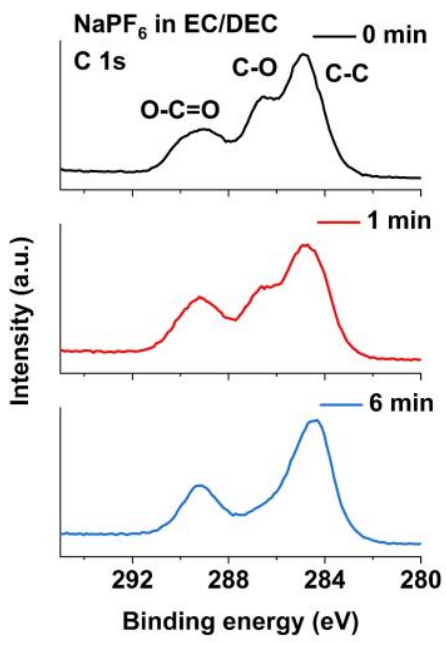

(b)

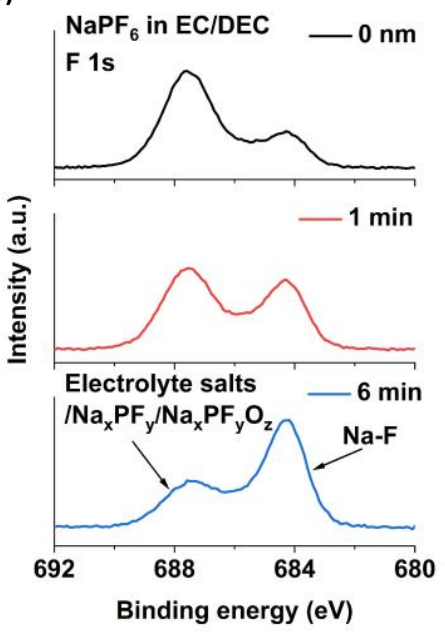

(c)

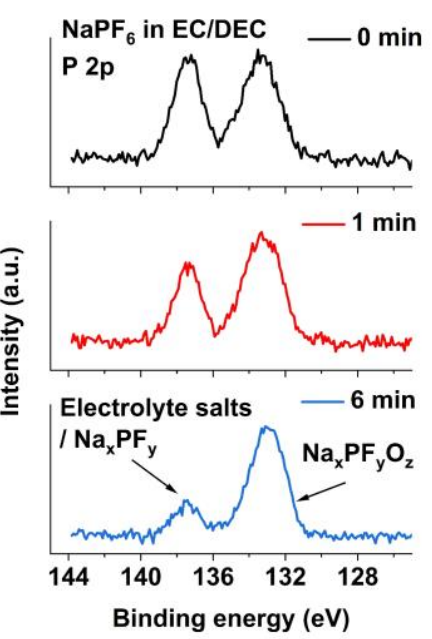

Figure S12. Etching depth profile of C 1s (a), F 1s (b), P 2p (c) in $\mathrm{NaPF}_{6}$ in EC/DEC

Furthermore, we studied the interfacial features of $\mathrm{CMK}$ in $\mathrm{NaPF}_{6}$ in EC/DEC. There are two main characteristic F 1s peaks in Figure. S11b, which are assigned to the electrolyte salts/ $\mathrm{Na}_{\mathrm{x}} \mathrm{PF}_{\mathrm{y}} / \mathrm{Na}_{\mathrm{x}} \mathrm{PF}_{\mathrm{y}} \mathrm{O}_{\mathrm{z}}$ at $687.3 \mathrm{eV}$ and $\mathrm{NaF}$ species at $684.0 \mathrm{eV} .{ }^{1}$ The $\mathrm{F} 1 \mathrm{~s}$ assignment and the $\mathrm{P}$ $2 p$ doublet peaks are the main components for SEI layer (Figure.S11c). Note that the intensity of $\mathrm{NaF}$ and $\mathrm{Na}_{\mathrm{x}} \mathrm{PF}_{\mathrm{y}} \mathrm{O}_{\mathrm{z}}$ increased during $6 \mathrm{~min}$ of $\mathrm{Ar}$ sputtering while the electrolyte salts/ $\mathrm{Na}_{x} \mathrm{PF}_{\mathrm{y}}$ decreased (Figure. S12b, 12c), indicating that $\mathrm{NaF}$ and $\mathrm{Na}_{\mathrm{x}} \mathrm{PF}_{\mathrm{y}} \mathrm{O}_{\mathrm{z}}$ exists in the inner layer of the SEI on CMK electrode. The decreasing intensity of carbon in Figure. S11d and Figure. S12a indicates the organic SEI layer in the outer surface of CMK electrode. 
(a)

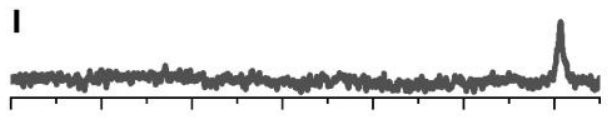

II

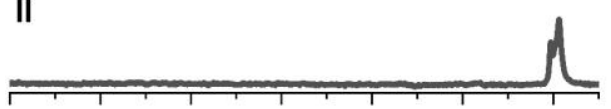

III

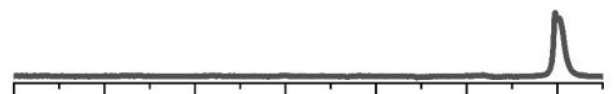

IV

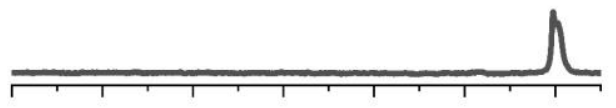

V

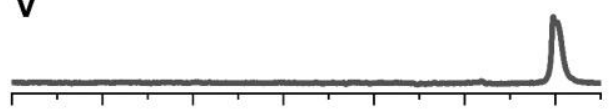

VI

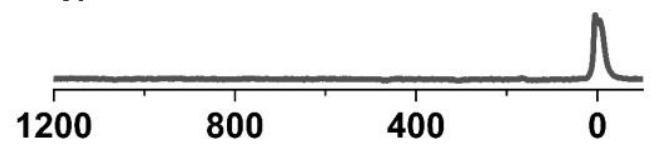

${ }^{23} \mathrm{Na} \delta \mathrm{ppm}$ (b)
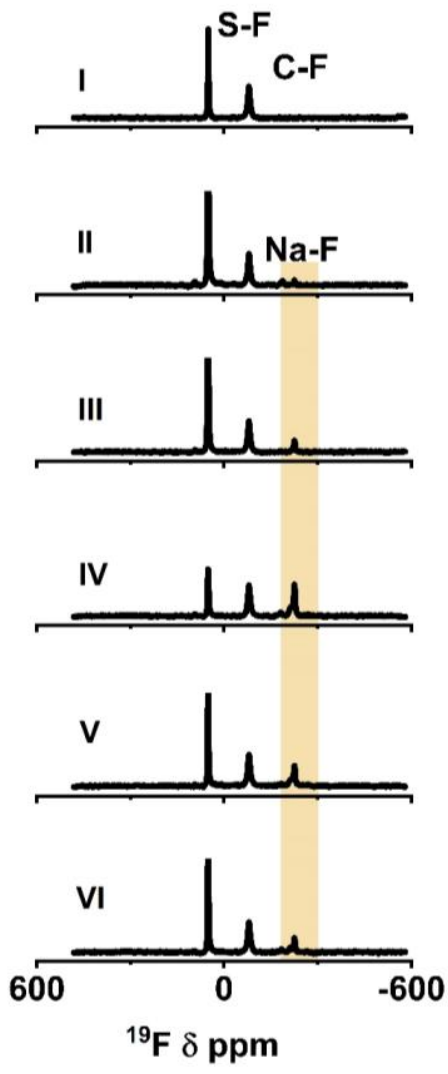

Figure S13. Ex situ ${ }^{23} \mathrm{Na}$ (a) and ${ }^{19} \mathrm{~F}$ (b) MAS NMR spectra of electrodes at different sodiation states (I-VI stages) in a full range ppm.

(a)

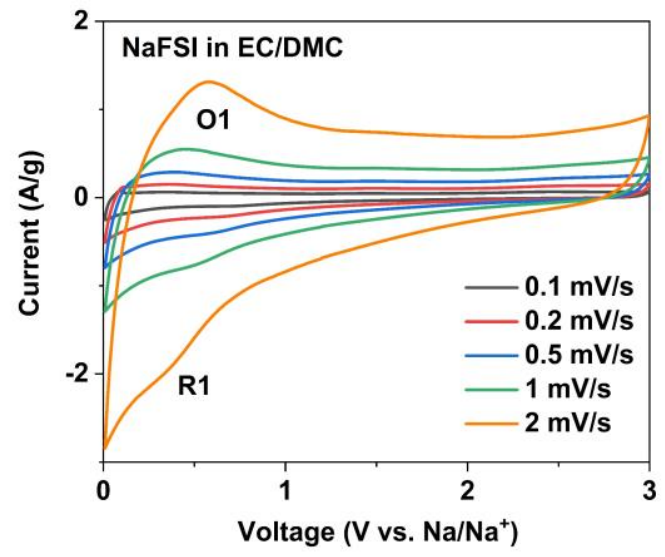

(b)

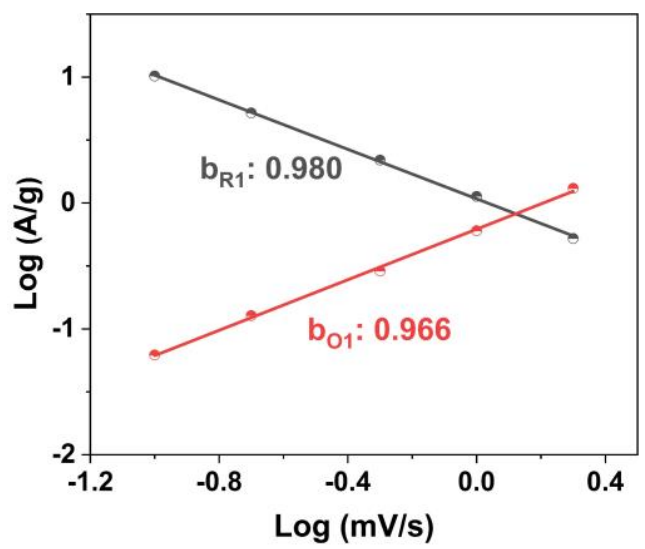

Figure $\mathrm{S14}$. $\mathrm{CV}$ curves of $\mathrm{Na} / \mathrm{CMK}$ cell in $\mathrm{EC} / \mathrm{DMC}$ at different scan rates from $0.1 \mathrm{mV} / \mathrm{s}$ to 2 $\mathrm{mV} / \mathrm{s}$ between $0.01 \mathrm{~V}-3 \mathrm{~V}$; (b) Fitted lines of $\log \mathrm{I}$ versus $\log \mathrm{v}$ lines at different redox peaks. 


\section{REFERENCES}

(1) Eshetu, G. G.; Diemant, T.; Hekmatfar, M.; Grugeon, S.; Behm, R. J.; Laruelle, S.; Armand, M.; Passerini, S. Impact of the Electrolyte Salt Anion on the Solid Electrolyte Interphase Formation in Sodium Ion Batteries. Nano Energy 2019, 55, 327-340. https://doi.org/10.1016/j.nanoen.2018.10.040. 